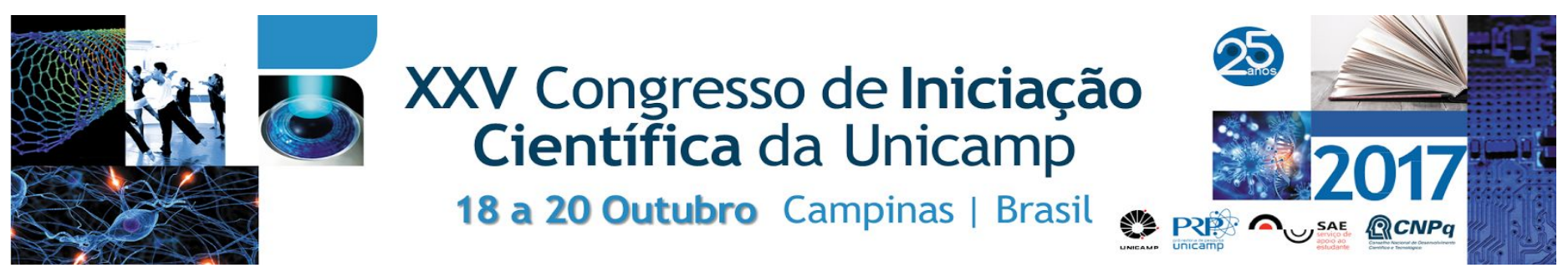

\title{
Métodos de Ensaios Aplicados aos Materiais de Construção: Madeira e ao Concreto
}

\author{
Gabriel C. Oliveira*, Juliane dos Santos*, Régia Possidonio*, Nádia S. Veiga, Mônica Ruy, Paulo G. K. Nunes, \\ Eduardo T. Fernandes, Julio Soriano.
}

\section{Resumo}

Conhecer as propriedades físicas e mecânicas dos materiais é importante para se determinar o uso adequado na construção civil. Esta pesquisa teve como objetivo conceituar propriedades da madeira e do concreto aos alunos do PIBIC EM, e obtê-las através de ensaios realizados em laboratório. Para o concreto foram confeccionados três traços para resistências distintas. Para a madeira foram realizados ensaios de compressão paralela às fibras em duas espécies: Pinus (Pinus ssp) e Cupiúba (Goupia glabra). Os resultados mostraram que para o concreto a resistência à compressão é muito influenciada pela relação água-cimento e a resistência à compressão da madeira é influenciada nas diferentes espécies. Conclui-se que algumas das propriedades dos materiais artificiais (concreto) são controladas na produção, enquanto que na madeira que é um material natural as propriedades dependem da espécie, da direção anatômica e da umidade.

\section{Palavras-chave:}

Resistência à compressão, densidade, teor de umidade.

\section{Introdução}

Os materiais de construção civil são caracterizados por propriedades físicas e mecânicas, determinadas por procedimentos normatizados em laboratório. Dentre os materiais usuais, a madeira tem suas propriedades influenciadas por fatores como a espécie e o teor de umidade, enquanto que o concreto tem suas propriedades definidas pela relação água/cimento utilizada na dosagem. Neste contexto, os bolsistas participaram de atividades junto ao Laboratório de Materiais e Estruturas da FEAGRI, cumprindo os objetivos de conhecimento da base científica e tecnológica de métodos de ensaios convencionais e métodos não destrutivos.

\section{Resultados e Discussão}

Foram proporcionadas bases teóricas através de palestras e estudo dirigido em textos técnicos. Dentre as atividades práticas, foram realizados ensaios para caracterização mecânica e física do concreto e madeira. Para o concreto, corpos de prova cilíndricos $(100 \mathrm{~mm} x$ $200 \mathrm{~mm}$ ) foram confeccionados com três traços distintos, variando-se a relação a/c, os quais foram submetidos à compressão simples (Figura 1a). Para cada espécie de madeira foram confeccionados corpos de prova prismáticos (50 mm x $50 \mathrm{~mm} \times 150 \mathrm{~mm}$ ), os quais foram submetidos à compressão paralela às fibras (Figura 1b). Resultados encontram-se na Tabela 1.

Tabela 1. Resistências médias à compressão (MPa).

\begin{tabular}{|c|c|c|c|c|}
\hline \multicolumn{3}{|c|}{ Concreto (Relação a/c) } & \multicolumn{2}{c|}{ Madeira } \\
\hline 0,49 & 0,59 & 0,77 & Pinus & Cupiúba \\
\hline 25,1 & 15,7 & 9,2 & 38,5 & 56,6 \\
\hline
\end{tabular}

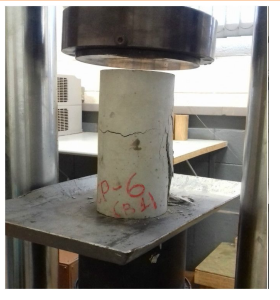

(a) concreto

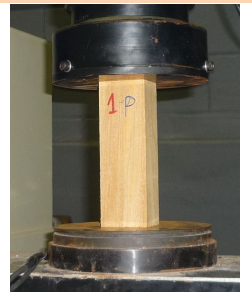

(b) madeira
Figura 1. Ensaio de compressão simples.

No caso do concreto, o aumento na relação de água cimento proporcionou variações na resistência à compressão em até $172 \%$. A espécie de madeira Pinus cuja densidade resultou $61 \%$ em relação à da espécie Cupiúba, apresentou uma resistência à compressão paralela às fibras $47 \%$ menor que a Cupiúba, mostrando a influência da densidade (espécie) nesta propriedade mecânica.

\section{Conclusões}

A partir dos ensaios foi possível concluir que mesmo para materiais de mesma natureza (natural ou artificial), as propriedades podem ser distintas por fatores próprios de cada material. Essas propriedades devem ser conhecidas para o uso adequado do material.

\section{Agradecimentos}

Ao CNPq pelas bolsas de Iniciação Científica, à Faculdade de Engenharia Agrícola (FEAGRI/UNICAMP) e ao FAEPEX pelo auxílio à pesquisa.

Associação Brasileira de Normas Tecnicas. NBR 7190 Projetos de estruturas de madeira. Rio de Janeiro: ABNT, 1997, 107 p.

L. A. Falcão Bauer. Materiais de construção. Rio de Janeiro: Livros Tecnicos e Científicos Editora S. A., 1979, 529 p. 